\title{
Detection of the effects of lead exposure by visual evoked response latency
}

\author{
DENNIS M. FEENEY, J. F. LONGO, and M. A. COSDEN \\ University of New Mexico, Albuquerque, New Mexico 87131 \\ and \\ H. ZENICK and R. PADICH \\ New Mexico Highlands University, Las Vegas, New Mexico 87801
}

\begin{abstract}
Visual evoked responses were studied in the offspring of mother rats exposed to lead acetate. All measurements were taken by experimenters uninformed regarding treatment assignment. The latency of the P2 component was significantly shorter for the lead-exposed animals than for the control animals. It is suggested that VER latencies may be a sensitive index of subclinical effects of lead on brain, long after discontinuation of lead exposure and when blood levels are normal.
\end{abstract}

While the incidence of clinical cases of lead $(\mathrm{Pb})$ poisoning has become rare, the general exposure to $\mathrm{Pb}$ has increased and an interest has developed in detecting subclinical effects of $\mathrm{Pb}$ ingestion (Waldron $\&$ Stofen, 1964). Recent reports have described retarded learning ability (Brody, Herrera, \& Zenick, $1975)$ in rats exposed to $\mathrm{Pb}$ early in life. Similar impairments in development have been reported in children with blood concentrations of $\mathrm{Pb}$ previously considered "normal," (de la Burde \& Choate, 1975) and high levels of $\mathrm{Pb}$ have been found in children with learning disabilities (Phil \& Parkes, 1977). Impaired vision has been reported in monkeys (Bushnell, Bowman, Allen, \& Marlae, 1977) following low levels of $\mathrm{Pb}$ exposure, and the latency of the visual evoked response (VER) in rats is reported to be very sensitive to mercury poisoning (Zenick, 1976). The present study was undertaken to examine the utility of the VER in detecting persistent effects of early $\mathrm{Pb}$ exposure on brain function.

\section{METHOD}

\section{Subjects}

The 2670 - to 80 -day-old male $\mathrm{CD}$ rats used in this study were offspring of mothers born in the Highlands University colony. The mothers had been weaned at 21 days of age and randomly assigned to $\mathrm{Pb}$ or control conditions and treatment begun.

\section{Procedure}

The treated mothers received $750 \mathrm{mg} / \mathrm{kg}$ of $\mathrm{Pb}$ acetate daily, dissolved in their drinking water. Intake of the correct dosage was assured by water depriving the mother and offering the $\mathrm{Pb}$ acetate in an amount of distilled water that the animal would consume entirely. The treated water was available from 02 .

Supported by NIH Grants MBS 5506 RR08066 and NS 10469-
6:00 p.m. to 8:00 a.m. daily, followed by free access to tap water until noon to provide adequate total water intake. Control animals were placed on a similar drinking schedule, and both groups had free access to Purina Lab Chow.

Potential dams were exposed to $\mathrm{Pb}$ from time of their weaning (21 days of age) until their pups, the subjects in this experiment, were weaned. Mating was initiated between 90 and 100 days of age. This 70-80-day pregestational exposure period was of sufficient duration to insure a steady-state level of $\mathrm{Pb}$ in blood (Castellino \& Aloj, 1964). Exposure of the mothers to $\mathrm{Pb}$ acetate continued through the 21-day periods of gestation and lactation. During nursing, the water bottles were situated so that only the mother could drink water. Thus, the total duration of dam exposure was approximately $112-122$ days.

$\mathrm{Pb}$ blood analyses have been conducted on animals treated in a fashion identical to that of the present study. The duplicate sample analyses were conducted by ESA, Bedford, Massachusetts. On Day 1 of gestation, the $\mathrm{Pb}$ blood level of the $\mathrm{Pb}$-acetate-exposed dam is $110 \pm 6.54 \mu \mathrm{g} / \%$, and at Day 21 of lactation (weaning), it is $117 \pm 11.49 \mu \mathrm{g} / \%$. At these time periods, the control dams have less than $4 \mu \mathrm{g} / \%$. The pups of both the control and the $\mathrm{Pb}$ exposed dams at the time of electrophysiological testing have $\mathrm{Pb}$ blood levels of less than $4 \mu \mathrm{g} / \%$.

The pups of $\mathrm{Pb}$-treated and control-group mothers were weaned at 21 days of age, tailmarked, and housed in group cages with free access to food and tap water. These offspring, the subjects in this experiment, received no direct $\mathrm{Pb}$ treatment. When the pups reached 70-80 days of age, they were transferred to the University of New Mexico for electrophysiological testing. These experimenters were kept uninformed of the group assignments until completion of data collection.

For recording, the rats were anesthetized with alpha chloralose (75 mg/kg IP; $30 \mathrm{mg} / \mathrm{ml}$ in propylene glycol), and when necessary, local anesthesia (xylocaine, 2\%) was injected into scalp and pressure points, since higher dosage of chloralose had killed several animals. The rat was placed into a stereotaxic device, the scalp opened, and a small burr hole made over occipital cortex ( $2 \mathrm{~mm}$ lateral from the midline and $1.5 \mathrm{~mm}$ anterior to lambda). Evoked responses were elicited by a Grass photostimulator at 5-sec intervals. The experiment was conducted in a dimly lit room with the photostimulator set at maximum intensity and placed $1 \mathrm{~m}$ directly in front of the animal. This yields a flash intensity of approximately $5 \mathrm{fc}$. A silver ball electrode placed on the dura recorded responses which were amplified by a Grass polygraph and 
monitored on a Tektronix storage oscilloscope. On-line averaged waveforms were obtained using a Linc 8 computer which displayed the waveform, and a movable cursor provided accurate measurements of the peak latencies of the VER components. Averaged VERs were obtained for 24 responses over a 500 -msec poststimulus period. A set of five averaged waveforms was obtained for each animal, and the latencies were measured to each of four prominent components. These separate averages assured the stability of the preparation and reliability of the measurements. The latencies from each averaged waveform were then combined so that the final peak latency measurements were based on 120 responses for each animal. At the conclusion of testing, the animals were killed by barbiturate overdose.

\section{RESULTS}

Complete sets of data were obtained from 17 animals, $8 \mathrm{~Pb}$ exposed and 9 controls matched for age and strain. Nine of the original 26 animals died either from unknown causes or anesthetic overdose in early experiments. The mortality rates were similar for the lead (4 of 12) and control (5 of 14) animals. Although the $\mathrm{Pb}$ group had lower body weights than controls at birth and weaning, there were no significant differences in weight at the time of electrophysiological testing.

The averaged VER consisted of four clear components identical to that described by Zenick (1976). The second positive peak (P2) was most readily identifiable across animals and was chosen for first analysis. An analysis of variance of the latency to P2 indicated a significant difference between the $\mathrm{Pb}$ and control groups. The latency of the $\mathrm{Pb}$ exposed animals to P2 was dramatically shorter than was that of the control group $(F=7.643, p<.015)$. Subsequent analyses of the latency data for the other components revealed no significant differences (see Table 1). Amplitude measurements were too variable for any interpretations or statistical significance, which is generally true for between-subjects designs using evoked potentials.

\section{DISCUSSION}

There are two interesting aspects of the data. First, flash evoked responses can differentiate $\mathrm{Pb}$ exposed animals from controls even 2 months after termination of a treatment that yields no enduring gross behavioral differences. The $\mathrm{Pb}$-exposed animals could not be distinguished from controls by routine observation of their general physical condition or spontaneous behavior in their home cages. However, impaired learning ability has been reported using this same $\mathrm{Pb}$-dosage procedure (Brody et al., 1975). The second interesting aspect of this data is the direction of the effect: a shorter latency VER $\mathrm{P} 2$ component in $\mathrm{Pb}$-exposed animals than in the controls. Several experiments (Mourek, Himwich, Myslevicek, \& Callison, 1967; Salas \& Cintra, 1973) have demonstrated that undernutrition of rats during
Table 1

Means (M) and Standard Deviations (SD) of Peak VER Latencies for Control and Lead Exposed Animals

\begin{tabular}{lrrrr}
\hline & P1 & N1 & P2* & N2 \\
\hline \multicolumn{5}{c}{ Control } \\
M & 37.8 & 54.5 & 86.3 & 114.0 \\
SD & 7.5 & 7.0 & 14.5 & 26.5 \\
& & Lead & & \\
M & 31.6 & 48.0 & 66.4 & 87.3 \\
SD & 15.2 & 11.9 & 15.2 & 25.9 \\
\hline
\end{tabular}

$p<.015$.

early development results in longer latencies to evoked potential peaks, especially for the VER. Therefore, the direction of the effect observed in the present study is particularly important, since it differentiates the effect of $\mathrm{Pb}$ exposure from fetal and neonatal undernourishment which has been a problem in $\mathrm{Pb}$ toxicology studies. While the $\mathrm{P} 2$ component had a significantly shorter latency in the $\mathrm{Pb}$ exposed animals than in the controls subjects, the N2 component also had a shorter latency but did not reach statistical significance, perhaps because of the large variance. With a greater number of subjects, both components may have a significantly shorter latency, but this and other issues will be more readily clarified using chronic unanesthetized preparations.

We believe that our results represent a cortical, rather than peripheral, effect of $\mathrm{Pb}$ exposure, since it is generally agreed that the late components reflect the response of cortical neurons and there were no significant differences between $\mathrm{Pb}$ and control groups for the early components. Additionally, visual deficits attributed to $\mathrm{Pb}$ ingestion in man are attributed to CNS damage and only rarely to peripheral effects (Grant, 1974). Whether the evoked response changes reflect intracortical mechanisms or changes in long-latency volleys from the nonspecific thalamus remains to be determined.

Recent data from experiments using $\mathrm{Pb}$ dosage procedures similar to the present study indicate a particular vulnerability of Golgi type II cortical neurons to $\mathrm{Pb}$ exposure (Murray, Gurule, \& Zenick, 1979). If such neurons mediate cortical inhibition (Colonnier, 1966; Feeney \& Orem, 1971), a loss of inhibitory interneurons may result in increased cortical excitability and shortened VER latencies. This may also contribute to the seizures observed with $\mathrm{Pb}$ poisoning (Waldron \& Stofen, 1964). Whatever the mechanism, the VER may be a useful diagnostic and research tool for $\mathrm{Pb}$ toxicology.

\section{REFERENCES}

Brody, K., Herrera, Y., \& Zenick, H. Influence of parental lead exposure on subsequent learning ability in offspring. Pharmacology, Biochemistry \& Behavior, 1975, 3, 561-565. 
Bushnell, P. J., Bowman, R. R., Allen, J. R., \& Marlae, R. T. Scotopic vision deficits in young monkeys exposed to lead. Science, 1977, 196, 333-335.

Castellino, N., \& Aloj, S. Kinetics of distribution and excretion of lead in the rat. British Journal of Industrial Medicine, 1964, 21, 308-315.

Colonnier, M. L. The structural design of the neocortex. In J. C. Eccles (Ed.), Brain and conscious experience. New York: Springer-Verlag, 1966.

de la Burde, B., \& Choate, M. S. Early asymptomatic lead exposure and development at school age. Journal of Pediatrics, $1975,87,638-641$.

Feeney, D. M., \& Orem, J. M. Influence of antidromic callosal volleys on single units in visual cortex. Experimental Neurology, 1971, 33, 310-321.

Grant, W. M. Toxicology of the eye. Springfield, Ill: Thomas, 1974.

MoureK, J., Himwich, W. A., Myslevicek, J., \& Callison, D. A. The role of nutrition in the development of evoked cortical responses in the rat. Brain Research, 1967, 6, 241-251.

Murray, H. M., Gurule, M., \& Zenick, H. Effects of lead exposure on the developing rat parietal cortex, DOE Symposium Series. Proceedings of the 17th Annual Hanford symposium, 1979, 520-535.

Phil, R. O., \& Parkes, M. Hair element content in learning disabled children. Science, 1977, 198, 204-206.

Salas, M., \& Cintra, L. Nutritional influences upon somatosensory evoked responses during development in the rat. Physiology \& Behavior, 1973, 10, 1019-1022.

Waldron, H. A., \& Stofen, D. Sub-clinical lead poisoning. New York: Academic Press, 1964.

ZENick, H. Evoked potential alternations in methylmercury chloride toxicity. Pharmacology, Biochemistry \& Behavior, 1976, 5, 253-255.

(Received for publication August 1, 1978; revision accepted April 23, 1979.) 